\title{
BREVE CARTOGRAFÍA DE LA RECIENTE PRODUCCIÓN TEATRAL BRASILEÑA: IMPROVISACIÓN, COMEDIA FÍSICA Y TEATRO CÓMICO POPULAR
}

\author{
Mariana MUNIZ \\ Universidade Federal de Minas Gerais (Brasil) \\ marianamuniz@ufmg.br
}

Resumen: La improvisación como espectáculo en Brasil tiene reciente trayectoria, empezando a afirmarse en el escenario teatral nacional a partir de 2001 con el estreno del espectáculo de improvisación de payasos, Jogando no Quintal en São Paulo. Desde entonces, influenciados o no por esta primera experiencia, podemos encontrar en la cartelera de las principales capitales brasileñas espectáculos de improvisación con fuerte tendencia a la comedia y al humor, como suele suceder también en otros países. Belo Horizonte, capital de Minas Gerais, se ha convertido en otro referencial de la práctica de la improvisación en Brasil con el estreno del primer Match de Improvisación del país en el 2006 y el I Festival Internacional de Improvisación Teatral - FIMPRO, realizado en 2008. Pese a su reciente presencia en Brasil, la improvisación como espectáculo encuentra en este país gran aceptación, vinculándose a la tradición de la improvisación popular y del teatro cómico. Este trabajo pretende analizar los principales espectáculos de improvisación humorísticos, estrenados en Brasil de 2004 hasta hoy, trazan- 
do una breve cartografía de la producción brasileña actual, evidenciando la vinculación de sus procedimientos dramatúrgicos a la comedia física y el teatro cómico popular. Los espectáculos analizados son: Jogando no Quintal (2004, São Paulo); Caleidoscópio (2008, São Paulo); Arena de Tolos (2005, Belo Horizonte); Match de Improvisación (2006, Belo Horizonte) e Sobre Nós (2008, Belo Horizonte).

Abstract: Improvisation as a performance form in Brazil has a recent trajectory, first taking root in the national theater scenery in 2001 with the clown improvisation performance, Jogando no Quintal, in São Paulo. Since then, either influenced or not by that first experience, we can find in the main Brazilian city capitals, improvisation performances with a strong tendency towards comedy and humor, as it commonly happens in other countries. Belo Horizonte, the capital city of the state of Minas Gerais, is another reference of improvisation practice in Brazil with the opening of the first Match d'Improvisation in the country in 2006 and the $\mathrm{I}^{\mathrm{st}}$ Festival Internacional de Improvisação Teatral - FIMPRO, in 2008. Despite its recent presence in Brazil, the improvisation as a performance form found great acceptance, associating itself to the popular improvisation tradition and that of the comic theater. The present communication intends to analyze the main improvisation representations since the ones first performed in Brazil in 2001 up to the present days, delineating a brief cartography of the present Brazilian production, as well as its scenic and dramaturgic choices. From the conception, the performances commented are: Jogando no Quintal (2004, São Paulo); Caleidoscópio (2008, São Paulo); Arena de Tolos (2005, Belo Horizonte). Match de Improvisación (2006, Belo Horizonte) and Sobre Nós (2008, Belo Horizonte).

Palabras-clave: Improvisación. Teatro brasileño. Contemporaneidad.

Key Words: Improvisation. Brazilian theater. Contemporaneity.

La improvisación teatral tiene diversas posibilidades de expresión artística y desarrollo técnico según los grupos que la practiquen en la contemporaneidad y sus propuestas estéticas e ideológicas. Por lo tanto, no se puede pensar en la creación ante el público como un contexto homogéneo. Es necesario aclarar a qué tipo de improvisación nos estamos refiriendo, para, a partir de ahí, estudiar sus propuestas estéticas. 
En Brasil, hay grupos que practican la improvisación como estrategia de movilización social y de espacio para la discusión de cuestiones importantes para determinada comunidad (Boal, 2003). Los Juegos Teatrales de Viola Spolin también representan un aporte metodológico que tiene largo recorrido en nuestro país, habiendo sido propulsores de nuevas metodologías que alían el juego al texto en una propuesta que contempla la producción, la recepción y la contextualización histórica del teatro. También existen aquellos grupos que practican la improvisación como estrategia de modificación de la relación usual entre actores y público, independientemente de la estructuración de una historia o conflicto. Así, entienden la improvisación como espacio de construcción de niveles de significado y comunicación más allá del entendimiento intelectual, rompiendo con la estructura dramática de la escena. Según Pavis:

Hay varios grados en la improvisación: la invención de un texto a partir de un boceto conocido y muy preciso (por ejemplo la Commedia dell'Arte), el juego dramático a partir de un tema o de una consigna, la invención gestual y verbal total sin modelo, y que va contra toda la convención o regla (Grotowski, 1971, el Living Theatre); la desconstrucción verbal y la búsqueda de un nuevo «lenguaje físico (Artaud)» (Pavis, 1996: 271).

Considerando la variedad de propuestas improvisacionales existentes en la escena brasileña contemporánea, pretendemos analizar en el presente trabajo una práctica incipiente de la improvisación ante el público, denominada Impro. Impro es el nombre que se suele utilizar en la definición de este campo de actuación, en relación directa con el título del primer libro de Keith Johnstone, Impro: improvisación y el teatro, una vez que las técnicas propuestas por el dramaturgo inglés son las principales referencias de este trabajo.

La Impro empieza a desarrollarse a partir de la segunda mitad del siglo Xx, influenciada por las propuestas de desbloqueo de la creatividad en el desarrollo de las habilidades narrativas propuestas por Johnstone y practicadas por su primer grupo, The Machine. Johsntone propone una técnica de entrenamiento del actor-improvisador, basada en la aceptación del fracaso como condición primordial para la creación, apostando al potencial de las primeras ideas que surgen y cuestionando la originalidad como valor absoluto de calidad. La necesidad de ser original, bloquea la capacidad creadora del artista, que ve en la repetición y, muchas veces, en la anulación de los primeros impulsos, la única manera de crear una obra de arte. 
Sus propuestas encuentran eco en diversos trabajos de artistas plásticos contemporáneos (Ostrower, 1976), músicos (Nachmanovitch, 1993), entre otros. El entendimiento de la creación artística como un proceso de aceptación del error, nos lleva a pensar que el entrenamiento no es necesariamente un ejercicio hacia la perfección, que, entendido comúnmente, sería cuando la obra podría mostrarse al público. El entrenamiento sería, también, obra de arte, algo que merece la atención y que, pese a que no sea perfecto, posee la tensión necesaria entre concreción y potencialidad. Es interesante percibir cómo, en diversas artes, la creación ante el público o, yendo más allá, la creación con el público, crece en la contemporaneidad. El centro cultural «104», localizado en la periferia de París, es un buen ejemplo de una propuesta de integración e interacción entre artistas y público en el momento mismo de la creación. En su página web, la misión del «104» se define:

Un lugar donde la dinámica artística rompe la frontera entre las artes y el público. De esta manera, en CIENTOCUATRO el arte y la cultura se abren a los espectadores y también a los transeúntes y curiosos. Esta fuerte orientación impulsa modos de fabricación, de producción y de visibilidad del arte decididamente nuevos. Los espacios de recepción y de trabajo del CIENTOCUATRO así como de la totalidad de la programación, fiestas y eventos serán pensados dentro de esta dinámica artística. Este acercamiento cree multiplicar las vías de acceso al arte y permitir aberturas inéditas hacia la creación contemporánea (www.104.fr) ${ }^{1}$.

Eso no quiere decir que, una vez que el error empieza a ser aceptado como parte de la obra, la falta de rigor, técnica o preparación sean características de la improvisación. La realización de un espectáculo totalmente improvisado exige que los actores sean capaces de dar forma a algo en el momento mismo que éste se presenta al público. Dar forma es, necesariamente, realizar elecciones entre uno u otro camino a seguir. Cuando se elige una propuesta, se eliminan las demás posibilidades. La opción entre uno u otro camino, puede llegar a hacerse de manera casi imperceptible, rutinaria, como alguien que anda por la calle y piensa dónde poner su pie para el próximo paso, sin que se dé cuenta de ello. En el caso de que la opción no sea acertada, puede fallar, pisar en falso, caer, pero siempre queda la posibilidad de hacer de la caída un paso de baile, como dice el poeta brasileño Fernando Sabino. Lo importante es pensar que, mientras se improvisa, damos forma, elegimos, y estas formas y opciones son, consciente o inconscientemente, definidoras de contenidos y significados:

\footnotetext{
1 Acceso en el 16 de abril del 2009. Trad. de Louisa Mari.
} 
El aspecto a ser considerado es que, por medio de ordenaciones, se objetiva un contenido expresivo. La forma convierte la expresión subjetiva en comunicación objetivada. Por eso, formar, crear es siempre ordenar y comunicar. De no ser así, no habría diálogo. En la medida en que entendemos el sentido de ordenaciones, respondemos con otras ordenaciones que son entendidas, a su vez, justamente en el sentido de su orden (Ostrower, 2008: 24)2.

En la búsqueda por el entrenamiento de la creatividad, Jonhstone encontró una propuesta teatral que, hasta hoy, reverbera en las carteleras de las principales ciudades de occidente: el Theatre Sports. El formato consiste en la disputa entre dos equipos de improvisadores a partir de desafíos lanzados uno a los otros. Los desafíos se solucionan a través de improvisaciones con un fuerte carácter cómico. A partir de los Theatre Sports hasta hoy, se han elaborado diferentes formatos y propuestas de espectáculos de improvisación en el universo de la Impro. Actualmente, se acordó dividirlos en dos categorías: formatos cortos y formatos largos. En los formatos cortos, los juegos, los desafíos y la metáfora del deporte se hacen más evidentes en improvisaciones rápidas que pueden durar de veinte segundos a siete minutos, aproximadamente. En los formatos largos, hay una búsqueda por la construcción de personajes con más profundidad e historias que tengan tiempo de desarrollarse sin una duración previamente establecida.

La Impro tiene una vinculación directa con el teatro cómico popular. Podemos establecer como referenciales históricos de esta práctica la Commedia dell'Arte, el Teatro de Feria y las tradiciones teatrales populares presentes en diversos países. La comedia física presente en estas tradiciones también es una característica del tipo de humor en la Impro actual. Así como en el clown, la Impro se hace por y para el público. No es que se haga lo que quiere el público, necesariamente, pero el espectáculo se realiza únicamente porque determinado público está allí para verlo y es con él que las historias van siendo construidas. Por lo tanto, hay una vulnerabilidad del actor ante algo que aún está por hacerse. Esta vulnerabilidad es, por esencia, cómica, pues lleva la posibilidad latente del error, de la exposición, de lo ridículo. Estar en desafío y aceptar esta condición, necesita una complicidad absoluta con el público. En el momento en que un juego es propuesto, un título del público es sorteado o que, en mitad de una improvisación, nada más funciona y la escena se hunde, el desespero o la resignación del improvisador ante su propio fracaso es risible. El público se identifica con él, pues sabe cual es la sensación de fracasar y, cuando el improvisador acepta su vulne-

\footnotetext{
2 Traducción de la autora.
} 
rabilidad, hay una especie de catarsis entre público y actores, cómplices en la posibilidad de perder. La vulnerabilidad por la aceptación del fracaso, forma parte de la trayectoria técnica y artística del payaso y es una de las características que lo fundamenta, así como lo es en la improvisación. El éxito, vencer al desafió de lo desconocido, también es celebrado en comunión, haciendo de los espectáculos de Impro un evento muy particular.

Otra particularidad que acerca los espectáculos contemporáneos de Impro al humor es la precipitación de la acción dramática. La corta duración de las improvisaciones, en los formatos cortos, hace que la historia y su desarrollo se den de manera precipitada, sin una vinculación causal creíble entre los acontecimientos. Así, surge el absurdo, la conexión entre dos elementos opuestos, la ruptura de la expectativa y demás características técnicas de la comicidad. En los formatos largos, la posibilidad de extender la acción dramática es una de las premisas para que estos espectáculos puedan desarrollarse en otros terrenos que no sea el del humor.

También existe la necesidad de conexión con el público. En la gran mayoría de los espectáculos de Impro, el público participa, eligiendo el mejor equipo o la mejor improvisación. Hay una votación realizada en cada escena que dice claramente a los improvisadores qué es lo que les está gustando y lo que no les gusta. Así, la búsqueda de la aprobación del público lleva al actor a explorar la comicidad, pues la risa es una reacción audible. Esta es una de las principales trampas para los improvisadores. En la búsqueda de la risa momentánea, puede ser que se mate una buena historia o que se bloqueen propuestas más interesantes. Con el tiempo, el público también se harta de reír siempre por lo mismo, quiere otro tipo de humor e, incluso, otro tipo de reacción frente a lo que se hace, no necesariamente cómica. Esta es una de las grandes cuestiones que han inspirado debates, artículos e, incluso, propuestas de espectáculos, en el universo brasileño de la Impro. El grupo Cia. do Quintal, uno de los principales responsables de la difusión de la Impro en Brasil, posee una publicación periódica regular que trata de los acercamientos entre el lenguaje del payaso y la improvisación. En una entrevista al grupo inglés Improbable, se discute el tema de la risa como estrategia de conexión con el público. Según Phelim McDermott, integrante del Improbable:

Sí, hay una trampa en la risa. Pero la respuesta no está sólo en la risa. La risa es lo más obvio, porque la oyes alto. Pero hay otras cosas. Es una pena que cuando se le pone la piel de gallina al público, eso no provoque un ruido, como un estallido, porque, entonces, oiríamos estos momentos también. Y en realidad el público adora ser estimulado de una forma diferente. [...] Si el 
público se ríe demasiado, acaba aburrido, porque duele, en realidad, reírse tanto. Tu tienes que hacerlos reír, después descansar un poco, pasar a otras emociones y, entonces, hacerlos reír al final. Si vas a estructurar un espectáculo, es eso lo que tienes que hacer (Abbud et al. 2007: 15)․․

En Brasil, el teatro cómico es una de las grandes referencias del público en las principales capitales del país. La predilección por comedias hace que gran parte de la producción teatral comercial de la actualidad sea de humor. Estos espectáculos se basan, muchas veces, en la afirmación de prejuicios culturales, raciales, sociales y de género. Así el gay, la mujer tonta y el cornudo inocente hacen parte del rol de personajes de estos espectáculos con gran influencia del vaudeville y del teatro de revista. Entretanto, no solo en el teatro comercial se trabaja la comedia. Existen espectáculos que logran ir más allá de este tipo de humor, invistiendo en una comedia que rompe con los patrones de comportamiento y propone, a través del humor, reflexiones sobre las relaciones del hombre en sociedad.

Los espectáculos de improvisación que analizaremos en este trabajo son ejemplos del acercamiento a la comicidad desde diversos puntos de vista artísticos e ideológicos. No es que pretendamos disminuir el valor artístico de la risa por la risa, atribuyendo al humor una necesidad de trascendencia que lo justifique. No creemos que tenga que haber una justificación para el humor, pues la risa forma parte de la manera en que los seres humanos se relacionan entre sí y con los acontecimientos que los rodean. Entretanto, es importante resaltar que no existe una neutralidad en el humor, siempre se ríe de algo y por algo. Así, la risa también es una manera de entender, valorar o despreciar determinada acción o comportamiento.

La improvisación ante el público provoca, necesariamente, una reestructuración de las relaciones entre aquel que actúa y aquel que recibe, pues la obra no está acabada. En una sociedad competitiva como la nuestra, donde, desde nuestros primeros pasos en el sistema educacional, solemos ser entrenados para la perfección, es interesante imaginar una obra abierta al error. Independientemente de los contenidos de las improvisaciones, la forma como se estructura la creación ante el público ya establece una ruptura con el valor de perfección y desdibuja las fronteras entre el creador y el receptor de la obra artística.

El humor basado en el prejuicio también suele aparecer en un espectáculo de improvisación y, muchas veces, ocurre a pesar de las convicciones ideo-

\footnotetext{
3 Traducción de la autora.
} 
lógicas que el improvisador afirma tener. Es molesto pensar que, pese a que no nos consideremos racistas, en una improvisación, por la intervención de asociaciones conscientes e inconcientes, lleguemos a dibujar una situación contraria a nuestras convicciones. Puede ser que se perciba demasiado tarde y que ya no haya cómo cambiar las cosas, pues se agotó el tiempo. Puede ser que el contenido de la Impro no sea percibido por el improvisador y éste necesite ser alertado por el público o sus compañeros. Es curioso pensar sobre lo que proyectamos, cuando no estamos cuidando tanto lo que decimos y hacemos. Los cambios suelen hacerse más profundamente cuando no se trata apenas de un discurso aprendido y, percibiendo nuestras contradicciones, trabajamos sobre ellas.

Jogando no Quintal es el primer espectáculo improvisado que conquistó espacio en la escena teatral contemporánea brasileña y determinó el surgimiento de un movimiento de improvisación teatral en este país. La propuesta surge del encuentro entre dos payasos, Márcio Ballas y César Gouvea, que trabajaban en la ONG paulista Doutores da Alegria. En su trabajo en el hospital, la improvisación fue una herramienta poderosa, pues, más que la risa o la escena, el trabajo del payaso en el hospital camina en el sentido de establecer un contacto real y transformador con los niños, sus padres o el staff hospitalario. Así, es necesario saber escuchar y adaptarse a lo que aquella relación específica exige a cada momento.

Márcio Ballas estudió en la Escuela de Jacques Lecoq en París y ya conocía el Match de Improvisación y, a partir de su estructura deportiva, planteó a César la posibilidad de un juego de payasos. El Match es un formato que tiene largo recorrido en la historia de la Impro. Creado en 1976 por Robert Gravel e Ivon Leduc, consiste en la disputa de dos equipos a través de improvisaciones. El público sugiere los títulos y vota por el equipo de su preferencia. El juego es una metáfora del hockey, deporte nacional en Canadá, y está reglamentado por dieciséis penalizaciones que corresponden a puntos al equipo adversario. Es una estructura muy cerrada, llena de reglas, algunas pertinentes a la propia técnica de improvisación y otras arbitrarias. En este contexto, parece difícil pensar cómo la anarquía propia del payaso podría funcionar.

Jogando no Quintal subvierte todas las reglas del Match, el juego es un pretexto para la creación y principalmente para la relación que se establece con el público. Este carácter subversivo, anárquico es, justamente, lo que hace de este espectáculo un ejemplo único en el universo de la Impro. Estrenado en 2001, en los fondos de la casa de César, con un público com- 
puesto por conocidos, la idea era improvisar entre amigos con algunas «caipirinhas». Desde entonces, Jogando no Quintal pasó por diversos espacios, cuadras polideportivas de colegio, tienda de circo y, actualmente, se presenta en uno de los teatros emblemáticos de Brasil, Tucarena en São Paulo. En cartelera hace siete años, el espectáculo reune, de viernes a domingo, a un público de cerca de mil personas por día. Entretanto, consigue mantener la sensación de intimidad e informalidad de un encuentro entre amigos.

Al llegar al teatro, el público es recibido por una banda de payasos que van saludando a algunas personas con canciones improvisadas. Luego entran los payasos-atletas, cada uno con su bandeja con «caipirinhas» y, mientras ofrecen la bebida al público, van estableciendo un contacto cara a cara, individualizado, que es determinante para el éxito de la función. No hay un tiempo determinado para que cada cosa ocurra; el tiempo es dilatado y el espectáculo llega a durar tres horas, con un breve intervalo de 10 minutos. Cuando realmente empieza la partida, vemos que el juez es una figura simbólica, no determina el orden, sino que cumple una función de maestro de ceremonias, explicando la estructura del espectáculo al público y estableciendo un contrapunto a las improvisaciones.

Describiremos una improvisación para intentar mostrar la dimensión del espectáculo. El juez pide al público un título y, en cierta ocasión, una persona dijo: sexo. De inmediato, los payasos empiezan a besarse exageradamente, uno de ellos va hacia el público y llama a una persona para la «orgía», otro lo sigue, y otro, y otro. Todos los payasos están ahora con alguien del público, fuera del escenario. Alguien propone que vayan todos al camerino, así todos salen de escena, los payasos con sus parejas del público, el juez, la banda. El público no entiende qué viene después y se mira estupefacto, el escenario sigue vacío. El técnico de luces apaga las luces del escenario y la gente se pregunta: ¿y ahora? ¿qué pasa? El técnico apaga las luces del público. Pasan algunos minutos. El público empieza a ovacionar y también a jugar a que se están besando. El técnico enciende las luces del público, uno a uno los payasos van volviendo, con la ropa rota, con un zapato de mujer y otro de hombre, absolutamente satisfechos. El público, entre carcajadas, aplaude. Es un acontecimiento, no solo un espectáculo. El público y los actores tienen la real sensación de que todo puede pasar en una ruptura de los límites usuales del espacio de la actuación.

Es curioso pensar que, mientras en la mayoría de los países la Impro se desarrolló teniendo el Match como primera experiencia, en Brasil lo primero fue, justamente, su subversión. La sociedad brasileña tiene cierta dificul- 
tad con la convivencia reglada, varias leyes existen, pero no son cumplidas, y se hacen más leyes para que se cumplan las leyes anteriores, muchas veces sin éxito. La informalidad es un valor intrínseco en las relaciones sociales, no hay una forma de tratamiento de cortesía que sea utilizada cotidianamente a no ser con personas muy mayores. Es un país, donde la mayoría de la población es joven y la juventud, por lo tanto, parece ser un valor incuestionable. No es nuestro objetivo, entretanto, entrar en un análisis sociológico del valor de la informalidad y la juventud en la formación de la identidad brasileña. Apenas sugerimos una posibilidad de punto de conversión entre el público de este país y el tipo de espectáculo que estamos describiendo.

El Match de Improvisación fue estrenado en Brasil, en Belo Horizonte, capital de Minas Gerais, en 2006. Su estreno ocurrió en el ámbito de la formación de actores en Centro de Formación Artística de la Fundação Clóvis Salgado. Presentado en la sala Ceschiatti, del Palácio das Artes, tuvo gran éxito, con un público encantado de descubrir una aproximación única entre teatro y deporte. Después de la primera temporada, los actores y la dirección decidieron continuar presentándolo. Con tres años en la cartelera de Belo Horizonte, habiendo participado en varios festivales nacionales e internacionales, el Match de Improvisación de la Liga Profissional de Improvisação es una de las principales referencias del género en Brasil:

No sorprende todo el éxito del Match de Improvisação en cartelera en el teatro Isabela Hendrix. El espectáculo de la Liga Profissional de Belo Horizonte, único en cada función, reúne un casting de rara calidad y fuerza creadora. [...] El formato, fusión de teatro y deporte, (...), trae a la escena lo que hay de más visceral en el trabajo del actor. Es la intuición y la técnica, exclusivamente, a servicio de la creación. El público, cómplice, dentro de las cuatro líneas, es parte activa del desarrollo de la acción (Fonseca, 2009: 20).

Por más logros que este montaje del Match pudiera tener, sigue siendo un formato ya creado y bien definido. Hay que aprender a jugar Match, pero, la capacidad creadora del actor está muy limitada por los estilos, duración y demás reglamentaciones del juego. Después de dos años jugando al Match, incluso en partidos internacionales, el grupo sintió la necesidad de crear un nuevo formato de espectáculo de improvisación. La propuesta era crear un espectáculo donde se reflejara la heterogeneidad de los componentes del grupo y sus propuestas y contradicciones personales y artísticas.

El espectáculo Sobre Nós (Sobre nosotros) surge de estas experimentaciones y se estrena en el FIMPRO-Festival Internacional de Improvisación Teatral, en el Teatro Alterosa, de Belo Horizonte, en 2008. En los procesos 
de ensayo, se buscó como referencial de las improvisaciones, fotos, diarios y memorias de los actores que eran reconstruidas y reformuladas en escena. Llegamos a una estructura dramatúrgica compuesta por tres historias, que se entrecruzan en una narrativa fragmentada y no lineal. Percibimos también que el impulso inicial, pese a que sea retirado de la realidad, se desprende en el momento de la creación, siendo trabajado como materia ficcional independiente. Otro hallazgo fue el de que el espectáculo partiría de historias que nos serían contadas por el público, mientras esperaba la abertura de las puertas del teatro. Así, los actores, minutos antes de la función, abordan personas del público y piden que les cuenten una historia, que va a ser el impulso inicial del espectáculo a crear aquella misma noche.

Con las historias en la mente, los actores vuelven al escenario. Abren el teatro al público. Mientras se llenan las butacas, se ve a los actores acordando lo que está por venir. Por tratarse de material extraído de la vida, o del recuerdo de lo vivido, las historias ya contienen un conflicto muy bien definido y los temas suelen ser las relaciones, los miedos, los desaciertos, los sueños... A partir de ellas, los actores van construyendo, en el instante mismo de la representación, una dramaturgia compleja, llena de encuentros y desencuentros, con multiplicidad de espacios, tiempos y situaciones.

$\mathrm{Al}$ inicio del espectáculo, un improvisador cuenta una historia a partir de sus memorias. Al final, vuelve el mismo actor y cuenta una historia muy parecida a la primera, pero con elementos totalmente diferentes. ¿Cuál es la verdadera? ¿Cuál la inventada? ¿Qué es real? ¿Qué es ficción? Son preguntas fundadoras del proceso de creación y que siguen presentes en el espectáculo.

Otro ejemplo de espectáculo de largo formato estrenado en el FIMPRO, en 2008, fue Caleidoscópio, de la Cia. do Quintal. Sin la nariz de payasos, cuatro actores de Jogando no Quintal, empezaron a investigar la construcción improvisada de historias largas a través de las relaciones entre los personajes. También en Caleidoscópio, y sin que hubiera un contacto previo entre los dos grupos, hay una propuesta de recuperación y ficcionalización de la memoria de los actores y del público. Entretanto, los formatos y sus propuestas estéticas son bastante diferentes.

En Caleidoscópio hay una relación con el público, que se acerca más a la del lenguaje del payaso. Las preguntas se formulan directamente y todos escuchan las respuestas. Son preguntas absurdas, que nos llevan a respuestas igualmente disparatadas. En medio de las respuestas del público, los improvisadores dan breves testimonios personales, surgidos por asocia- 
ción libre. Recogida toda la información necesaria, se empieza una única improvisación sin ningún tipo de reunión entre los actores para la definición de las pautas a seguir. La improvisación va incorporando personajes citados por el público, situaciones, detalles, sin atenerse a una sola respuesta. Se construye una narrativa lineal a partir de los fragmentos de los testimonios iniciales.

Pese a la linealidad temporal, propuesta por la improvisación, el juego de payasos sigue muy presente, rompiendo la historia en búsqueda de un detalle de la relación con el público. Así, se establecen dos campos de significado: el de la historia y el de la construcción de la misma. Estos campos se entrecruzan continuamente, evidenciando elecciones, desvíos y digresiones.

La comicidad sigue estando muy presente en ambos. En Caleidoscópio, las historias son de un humor delicado que surge del reconocimiento de lo ridículo de cada uno. En Sobre Nós, el humor es un elemento importante en la construcción de los personajes, pero no se quiere producir necesariamente una risa suelta o una carcajada. Los personajes están «al borde de un ataque de nervios», en situaciones extremas, donde es fácil perder los papeles. Mientras que en Sobre Nós, los personajes están traspasados por una realidad que les hace comportarse de manera exagerada y compulsiva, en $\mathrm{Ca}$ leidoscópio son personas delicadamente inadecuadas, que intentan encontrar su espacio y no lo consiguen.

En esta breve cartografía del teatro de improvisación brasileño dejamos, necesariamente, de hablar de muchos otros grupos y espectáculos que dinamizan a la escena contemporánea en este país, dentro del ámbito de la improvisación. Entretanto, la selección de estos espectáculos se justifica por tratarse de grupos que trabajan en las dos principales propuestas de la $\mathrm{Im}$ pro actual: el formato corto y el formato largo. Partiendo de espectáculos deportivos, basados en la competición, Cia. do Quintal y Liga Profissional de Improvisação han empezado a decantarse por espectáculos más teatrales, donde la construcción dramatúrgica y la relación de los personajes tengan tiempo de desarrollarse. En este desarrollo, la comicidad, pese a que siga teniendo una fuerte presencia, abre espacio a otras emociones y otras maneras de aproximación con el público.

La búsqueda del material en la memoria de los actores y del público hace que la propuesta de construcción conjunta de la escena en cada noche se radicalice. También las fronteras entre memoria, realidad y ficción son desdibujadas y el espacio de la creación se ve libre para su realización, momento a momento, frente al público, con el público y para el público. 
Así, ante la multiplicidad de la escena teatral contemporánea brasileña, la improvisación como espectáculo se viene abriendo espacio desde el inicio del siglo XXI. Actualmente, son varios los grupos que la practican en diversas ciudades del país y, pese a que su desarrollo inicial esté muy vinculado a los formatos deportivos, van surgiendo propuestas de otros formatos que buscan otro tipo de relación con la risa, con la construcción de historias improvisadas y con el público. Conectados con los principales grupos de Impro de Hispanoamérica, a través de la realización de diversos festivales internacionales, la Impro brasileña va dibujando su espacio y esbozando su personalidad artística.

\section{REFERENCIAS BIBLIOGRÁFICAS}

ABUUD, V. et al. (2007). «Entrevista Improbable». A Chuteira: Revista sobre palhaço e improvisação 1.4 (julio-agosto), 15-18.

BOAL, A. (2003). O Teatro como Arte Marcial. Rio de Janeiro: Garamond.

FONSECA, J. da (2009). «A Criação é o Show». Estado de Minas. Sexta-feira, 20 de fevereiro, 20.

JOHSNTONE, K. (2000). Impro: Improvisación y el teatro. Santiago de Chile: Cuatro Vientos Editorial.

LEHMANN, H.T. (2007). Teatro Pós-dramático. São Paulo: Cosacnaify.

MUNIZ, M. (2005). La improvisación como espectáculo: principales experimentos y técnicas de aprendizaje del actor-improvisador. Tesis de Doctorado (inédita). Alcalá de Henares: Universidad de Alcalá.

NACHMANOVITCH, S. (1993). Ser criativo. O poder da improvisação na vida e na arte. São Paulo: Summus Editorial.

OSTROWER, F. (2008). Criatividade e Processos de Criação. Petrópolis: Ed. Vozes.

PAVIS, P. (1996) Diccionario del teatro. Dramaturgia, estética, semiología. Buenos Aires: Paidós Comunicación.

SPOLIN, V. (2002). Improvisação para o Teatro. São Paulo: Ed. Perspectiva. www.104.fr. Acceso el 16 de abril de 2009. 